A recent development in the field of general medicine has been the establishment by several universities of seminars in general medicine. It is hoped that chairs in general medicine will soon follow. We have also started special vocational training seminars in general practice. Apart from general practice topics other subjects to be included are environmental problems, preventive medicine, and health education.

From 1 January 1974 general practitioners and specialists will face quality controls of their laboratory tests, $x$-ray examinations, and, later on, their cytological examinations; if they fail the tests they will lose the right to carry out these examinations in their own practices.

General practitioners in the Federal Republic expect several improvements from membership of the E.E.C. The international contacts should lead to agreements regarding the training of teachers, educational criteria, and standards-in fact an improvement in the quality of medical services as a whole.

Stuttgart, Federal Republic of Germany

S. HÄUSSLER, M.D., General Practitioner

\section{*Women in Medicine}

\section{Great Britain}

\section{ROSEMARY RUE}

At present about one-fifth of doctors in Britain are women: they account in hospitals for $7.6 \%$ of consultants and in general practice for $11.6 \%$ of principals. Careers for women in medicine are, however, often achieved with difficulty, and women doctors frequently undertake jobs which lack the important element of job satisfaction. Lack of training has led many to accept work in assistant grades or in narrow aspects of specialties from which no advancement was possible. Some women doctors are not working at present because they cannot find employment opportunities which combine an appropriate training.

Women compete for medical school places and their applications are of high quality. Nearly a quarter of all British medical students were women in 1968, when the Royal Commission on Medical Educcation recommended that the main criteria for admission to a university medical school should be the applicant's ability to profit from the course and to become a good doctor irrespective of sex. This advice has gained broad acceptance. Now one-third of medical students are women (a total of 1,052 women in the October 1972 intake for the United Kingdom) and the argument is developing that a mixture of half men and half women is not only attainable but desirable on educational grounds. The government has announced its intention to study with the universities the avoidance of discrimination on the grounds of sex in their admission policies. At present, however, the actual mix is a policy matter for individual medical schools.

Difficulties arise for women doctors as a result of the trends and structure in a modern society which must be familiar throughout the developed world. Though it is important to take into account the individual needs of women who may become mothers at an earlier stage, the essential features of schemes aimed at avoiding wastage of women doctors is the provision of planned postgraduate training to allow them time to fulfil their role as mothers in parallel over these early years. In 1970 the first 100 women doctors in each of two schemes in N.H.S. regions were compared and closely similar results were demonstrated.

Women doctors follow the same career patterns as men until they have commitments to children-or elderly relatives. Thereafter, provided she can have intermittent short breaks for maternity leave, the typical women doctor will make progress with higher qualifications and build up her experience in medicine if she can pursue a programme

*At this session the chair was taken by the Baroness Elles, Chairman, British Section, European Union of Women which allows her to share her time between motherhood and medicine over an extended period. Most women can give about half as much time as a man during this period of their lives and they achieve a sufficient level of training and experience for a career post in a specialty six to eight years later than the men with whom they studied medicine as undergraduates.

Once trained to a career level, the average woman doctor can offer three-quarters of the time offered by a man for clinical service, some time still being needed by her for her home, teenage children, and elderly dependents.

It is most important that women medical students and young women doctors should have suitable career counselling to help them understand and plan their career patterns. To help the young mother keep in touch with her profession during the critical period when she may become dispirited and is potentially at risk of "wasting" her education a retainer scheme was started by the D.H.S.S. in 1972. This scheme offers a small payment for doctors temporarily unable to practise medicine if they will remain registered and insured and undertake a minimum amount of postgraduate education and supervised practice in the course of the year. The scheme is popular and appears to fill a need-it is a little too early to evaluate its effect but it should lead women on quite easily to the fuller programmed training already described.

If there are problems associated with women in medicine, are there any compensatory advantages ? A rapidly increasing proportion of the medical profession is required competently and willingly to undertake the care of patients with chronic disease, especially those of old age, and to help the expansion of psychiatry and preventive medicine. It is therefore very interesting to note that in the regional training schemes for women doctors the specialties which among an unrestricted choice are popular to the point of being oversubscribed are psychiatry, geriatrics, care of the young disabled, and rehabilitation. This is in marked contrast to the popularity of the surgical specialties with men. The signs are that an increased entry of women to medicine and their full training and employment would result in the eventual career choice which the N.H.S. needs. It seems fortunate that men and women tend to have different, complementary gifts to bring to medicine.

Oxford Regional Hospital Board

ROSEMARY RUE, M.B., D.C.H., Senior Administrative Medical Officer

\section{Italy}

\section{SILVIA D'ANCONA}

The acceptance of women in medicine has come about largely in this century and particularly in the last few years-though we know from history that women have played their part in medicine for centuries. Today in Italy most women doctors work in the large towns, and many specialize in paediatrics; as such they can work as school doctors, in seaside or mountain health resorts, and with the Mother and Child Health Service (Opera Nazionale Maternita ed Infanzia). Others specialize in neurology and child psychiatry, anaesthetics, and obstetrics and gynaecology. More men practise surgery, orthopaedics, and dermatology, and the other specialties are followed equally by men and women. There are very few general practitioners in Italy.

No obstacles are imposed on the employment of women, either married or single; but obviously it is easier for single women to devote themselves to a full-time medical career. Those women who have continued their profession after marriage insist that day nurseries are an absolute necessity, and school meals and afternoon school also help.

Nowadays patients accept women doctors both in general practice and in hospital. But it is still relatively difficult for women to get university jobs. Gradually Italian women ase asserting themselves and becoming important in the seientific 